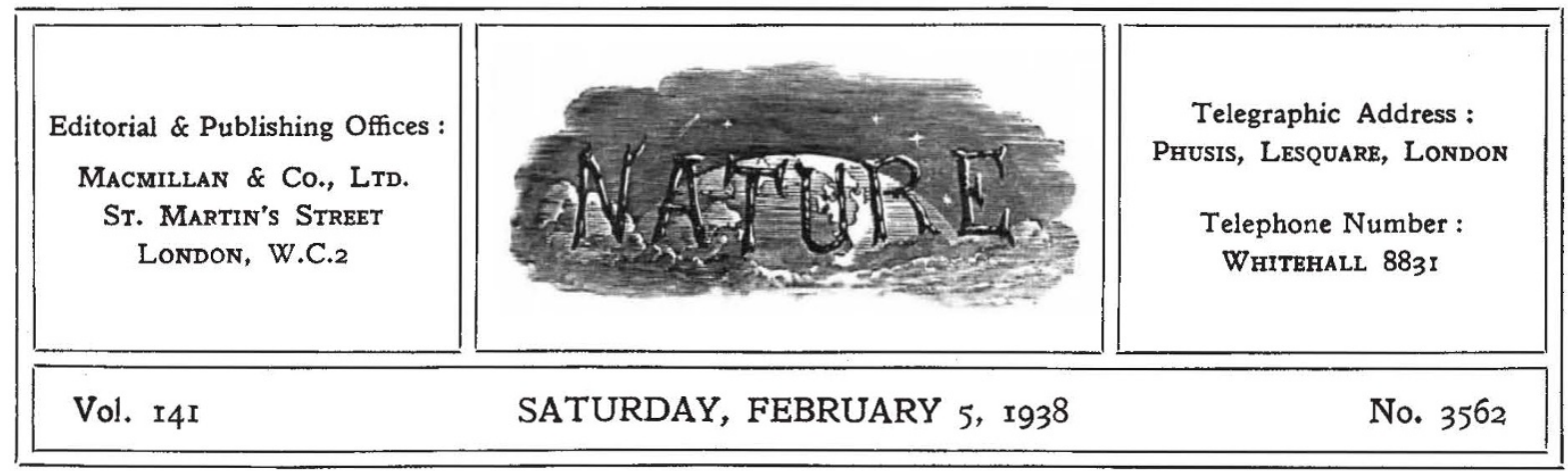

\title{
Science in Administration
}

$T^{\text {Hen }}$ $\mathrm{HE}$ position and functions of the scientific or technical expert have been the subject of many discussions and much difference of opinion. The general view of administrators is that "The expert should be on tap but not on top" ; but this arises from a widespread official assumption that intimate knowledge of a particular subjectunless it is of a literary or historical character-is a disqualification for an administrative post. The point of view of the professional civil servant was stated in a leading article in the November issue of State Service. The article suggests that a remedy of current social and economic maladjustment can only be found in the intensive use of the methods of scientific research and inquiry in problems which have hitherto generally been regarded as outside their province. If the achievements of the chemist, the physicist, the biologist and the engineer are to be correlated with the processes of public administration, and not stultified or misapplied through the inability or reluctance of politicians and administrators to appreciate the significance of new scientific development, the expert's processes of thought and action must be extended into fields of human activity where they are at present rarely encountered.

These reasons themselves have led the Institution of Professional Civil Servants to maintain insistently that, in the interests of efficient government, the heads of professional, scientific or technical branches of the Civil Service should be given an unconditional right of access to Ministers in charge of their department on all matters in which their special knowledge provides them with a particular qualification to advise. The soundness of this contention is now scarcely challenged, however practice may depart from the principle. There is, however, another point of view, which was very ably advanced by Dr. G. W. C. Kaye in his address to Section A (Mathematical and Physical Sciences) at the British Association meeting at Nottingham. Dr. Kaye challenged the dictum that qualities of leadership are more likely to be developed by the old humanitarian studies than by the natural or mechanical sciences, and ridiculed the idea that technical or scientific workers invariably require to be mothered by full-blooded non-scientific or quasi-scientific administrators.

A scientific training may be the medium for the development of latent administrative ability as much as any other career and probably more than most. Restriction of the opportunity of scientific men who possess administrative ability to advance to the highest positions of administrative responsibility, whether in the State service, in industry or elsewhere, is not only unfair to the scientific worker as a class but is also a danger to the State, by limiting the resources upon which it can draw for a type that in any event is not easy to find. The significance of this point is well illustrated in Sir Josiah Stamp's recent address on the administrator and a planned society to the Institute of Public Administration, although he nowhere referred to it explicitly.

Sir Josiah sees the problem of administration as fundamentally that of securing a greater fitness to achieve approved ends, rather than obtaining any vision of a changing task which might be more than a question of degree and involve a different type of administrator. The responsibilities of the administrator are now so wide and numerous that the question arises whether a new kind of administrative technique and ability is required, whether different aptitudes and temperaments are 
logically involved, and whether the mental training should have some radical redirection.

This question of the type of administrator is all the more important in that the further question of the type of administration required in modern society has been raised in many quarters, for example, in the study of "British Experiments in Public Ownership and Control" by Mr. T. H. O'Brien, promoted by the Institute of Public Administration, or Sir Daniel Hall's discussion of possible modifications in the administration of democratic Governments to promote planning and efficiency, recently contributed to the Nineteenth Century. The two questions are interlocked, but we cannot be sure that we are getting the best out of the existing system unless we are using the best type of administrator in that system.

Equally, of course, it is true that an existing administrative system may be condemned as inadequate because by recruiting on too narrow a basis or through other deficits it fails to obtain or develop the best type of administrator. For this reason the recently published series of essays on "The British Civil Servant", some of which originally appeared in the Political Quarterly, are of special interest and significance, particularly the essay by Mr. F. A. A. Menzler on the expert in the Civil Service, and the discussions of the recruitment and training of officers in the Civil Service and the Local Government Service.

It is indeed strange that in the multitude of books on planning there is little reference to the administrative problem, and the fact that the new responsibilities involved in such corporate enterprises demand new qualities and new skills which may be the very antithesis of those required in the development of a successful one-man concern is largely ignored. As Dr. Robson suggests in reviewing a century of municipal progress, a more constructive type of administrator is required who sees possibilities and opportunities rather than difficulties and dangers, and who possesses creative ability and the capacity to promote energetic and far-reaching projects.

Under such conditions administrative ability is of greater rather than less importance, even if we are concerned with a slightly different type of administrator. Technical factors have to be assessed, but possibly technical factors in not one but half a dozen or more fields, and the administrator must consider the indirect as well as the direct effects of the proposed action or policy. The task of the administrator in the future is, in fact, as Sir Josiah Stamp points out, increasingly to secure the maximum net social product, and success of a measure or policy cannot be judged merely by sectional statistics but only by the effect on the national welfare when all repercussions have been taken into account.

This in itself clearly indicates the unsuitability for such responsibilities of the business man of the single management type, accustomed to fixing his own goal and achieving it in a competitive world, as well as the exactly trained civil servant accustomed to the analytical application of a legislative programme in a statute and working to the elaboration of a completely static programme. As a corollary it again emphasizes the importance of tapping all channels to secure an adequate supply of men of the requisite ability and vision.

If, however, it is essential that the highest administrative posts should be recruited from the widest possible field, technical and scientific as well as others, the question of training as well as of final selection remains. In this field, the idea of the staff college has only been tentatively explored, and the possibilities of vocational selection in regard to the higher posts as distinct from entrance to industry have scarcely been probed. Indeed, vocational guidance only becomes possible when the requirements for the post to be filled can be defined with some exactitude.

Obviously in this field such bodies as the National Institute of Industrial Psychology, the Institute of Industrial Administration, and the Institute of Public Administration have important contributions to make. What, however, in the first instance delays progress is the general failure, due to mis-education, to realize that scientific research and technical advance are producing strains and stresses in the structure of society which, if they do not receive prompt attention, may bring about the destruction of the social order. The status of the specialist in the Civil Service is merely symptomatic of society's general attitude towards those who are reshaping social environment.

The present unsatisfactory position has been pointed out authoritatively on repeated occasions in recent years. A report of the British Science Guild in 1931 strongly condemned the inefficiency of the practice of excluding officers of the expert class from the important administrative positions responsible for the direction of the work, and contrasted this position with the success of the opposite policy pursued in large-scale progressive 
industry. The report of the Royal Commission on the Civil Service, which appeared almost simultaneously, disappointed any hopes of this position being rectified at an early date, and instead betrayed a fundamental failure to appreciate the significance of the expert in public administration. In contrast with this, the Bridgeman Committee, reporting on the Post Office in 1932, was the first public inquiry committee to give full recognition to the scientific expert in the Civil Service, and proposed in effect that he should take his place on level terms with the administrative expert and the financial expert, and have his say in the formulation of policy as in the control and execution of the routine operations.

There is thus at least one instance of public recognition of the principle that a technical man who has shown that he possesses administrative talent should be eligible for other appointments. Meanwhile progress is slow. In the Local Government Service, as has been pointed out in the P E P report and elsewhere, little or no attempt has been made to implement the recommendations of the
Hadow Report of 1934 regarding the recruitment, training and promotion of local government officers, and Sir Ernest Simon is still able to direct attention to our neglect of the universities in recruiting for this service, to the absence in many of our local rulers of the scientific quantitative thinking which is the basis of wise action in social affairs, and to the need of selecting and promoting men with a single eye to the highest degree of administrative ability. Here, no less than in the Civil Service itself, is there scope for the recruitment of administrators with a wider culture that embraces a real and intimate understanding, acquired from study, of the significance of science and scientific discovery in the evolution of modern society.

The contribution of the scientific or technical expert in every sphere of life grows more and more important, and the security of society makes it imperative that his services shall be fully and wisely used. Equally the burden upon the administrator grows heavier, and we can less than ever afford to miss the rare administrator of firstclass ability wherever he may be found.

\section{Origins and Growth of Chemistry}

\section{A Short History of Chemistry}

By Prof. J. R. Partington. Pp. xiv +386 . (London: Macmillan \& Co., Ltd., 1937.) 7s. 6d.

THE history of chemistry, like that of Ko-Ko, 1 "may rank with most romances", and lends itself perhaps too easily to the picturesque rather than to the accurate style of narration. As Dr. Sarton has recently observed, however, "accuracy is as fundamental in the historical field as in the scientific one, and .. . has the same meaning in both fields"; so that we may properly require an unswerving adherence to fact as the prime qualification of a historian of chemistry. The second qualification must be a first-hand acquaintance with as much as possible of the original literature and a critical familiarity with secondary authorities, while the third-of equal indispensability - is a sound knowledge of chemistry from the practical point of view. All these qualifications Prof. Partington possesses, happily backing them with a pleasant style and thus softening, without in the least obscuring, a precision of thought and an economy of words that might otherwise have appeared somewhat prim. That he has attained his expressed aim of being objective, impartial, and innocent of conventional platitudes, will be agreed by everyone who reads his present book, which affords a survey of chemistry from the earliest days to the first decades of the twentieth century.

After a preliminary chapter on ancient metallurgy, glass-making, and kindred arts, Prof. Partington deals with the origins of chemistry qua chemistry, adopting the generally accepted view that the birthplace of the science was Alexandria. He then describes, very briefly, the diffusion of alchemy in Arabia, India, China, and Europe. This chapter could well have been enlarged without upsetting the balance of the book, but even in its succinctness it makes clear what is not always understood, namely, that early Chinese alchemy of the centuries immediately preceding the Christian era dealt mainly with the medicine of immortality, in contrast to the transmutatory alchemy of the West, out of which chemistry arose. Incidentally, it may be remarked that Prof. Partington seems to be under some misapprehension about the "Sabeans" of Harran. The Syrian heathens of this celebrated ancient town called themselves Sabæans to avoid persecution from the Caliph Al-Ma'mun; the true Sabæans or Mandæans lived between Basra and Wasit, that is, in the region formerly known as Chaldea. 